\title{
Ocular signs in chronic renal failure
}

\author{
M. EASTERBROOK* $\ddagger$ AND G. B. MORTIMER** \\ From the Departments of Ophthalmology, Sunnybrook and Toronto General Hospitals, Toronto, \\ Canada
}

Past reports in the literature have stressed the occurrence of retinal detachment in pregnancy (Bosco I96I), chronic glomerulonephritis (Mettier, r96ı ; Buchanan and Ellis, I964; Lapco, Weller and Greene, 1965; Ellis and Fonken, I966; Sharpstone and Lee, 1966; Steiness, I968; Paris and Macoul, I969) diabetic nephropathy (Lapco and others, I965), and chronic pyelonephritis (Paris and Macoul, 1969). A leading article in the British Medical fournal (1966) stated that in uraemia retinal detachment should be regarded as an immediate indication for peritoneal or haemodialysis. We have therefore examined patients incapacitated by chronic renal failure with the slit lamp, fundus photography, and fluorescein angiography to identify the ocular manifestations of the condition and assess their value as indicators for dialysis. A new conjunctival finding is also described in the following paper.

Table Thirteen cases of chronic renal failure (26 eyes)

\begin{tabular}{|c|c|c|c|c|c|c|c|c|}
\hline \multirow[b]{2}{*}{$\begin{array}{l}\text { Case } \\
\text { no. }\end{array}$} & \multirow[b]{2}{*}{$\begin{array}{l}\text { Age } \\
\text { (yrs) }\end{array}$} & \multirow[b]{2}{*}{ Sex } & \multirow[b]{2}{*}{ Diagnosis } & \multirow{2}{*}{$\begin{array}{l}\text { Blood } \\
\text { pressure }\end{array}$} & \multirow{2}{*}{$\begin{array}{l}\text { Blood urea } \\
\text { nitrogen } \\
(m g . / 100 \mathrm{ml} .)\end{array}$} & \multicolumn{2}{|l|}{ Serum } & \multirow{2}{*}{ 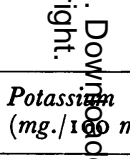 } \\
\hline & & & & & & $\begin{array}{l}\text { creatinine } \\
(\mathrm{mg} . / \mathrm{r} 00 \mathrm{ml} .)\end{array}$ & $\begin{array}{l}\text { Calcium } \\
(\mathrm{mg} / \mathrm{I} \text { 100 } \mathrm{ml} .)\end{array}$ & \\
\hline I & 22 & $\mathbf{M}$ & GN & $220 / 110$ & 87 & 13.5 & $8 \cdot 0$ & 6.8 巳 \\
\hline 2 & 28 & $\mathbf{M}$ & GN & I 75/ I I 3 & 130 & $21 \cdot 5$ & 10.4 & 6.9 욱 \\
\hline 3 & 32 & $\mathbf{M}$ & $\mathrm{GN}+\mathrm{PN}$ & I $70 / 90$ & 117 & $19 \cdot 2$ & $8 \cdot 3$ & 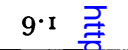 \\
\hline 4 & 32 & $\mathbf{M}$ & GN & เ $90 / 96$ & 57 & $3^{1 \cdot 2}$ & $7 \cdot 6$ & 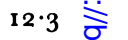 \\
\hline 5 & 34 & F & PN & I Io/90 & 183 & I $1 \cdot 9$ & $6 \cdot 5$ & $10.0 \dot{\sigma}$ \\
\hline 6 & 34 & $\mathbf{M}$ & GN & $180 / 110$ & 150 & $30 \cdot 0$ & $5 \cdot 3$ & I I · 0 \\
\hline 7 & $4^{6}$ & $\mathbf{M}$ & PC & $170 / 110$ & I 53 & $23^{\circ} 0$ & $10 \cdot 6$ & I I.6 \\
\hline 8 & $4^{8}$ & $\mathbf{M}$ & PG & $150 / 100$ & 90 & $12 \cdot 0$ & $7 \cdot 6$ & $6 \cdot 1$ 윽 \\
\hline 9 & 49 & $\mathbf{M}$ & GN & $240 / 120$ & 77 & $9 \cdot 5$ & $8 \cdot 3$ & $7 \cdot 5$ 을. \\
\hline 10 & 56 & $\mathbf{M}$ & $\mathrm{AN}$ & $160 / 80$ & 86 & I $1 \cdot 9$ & $8 \cdot 7$ & $5.7 \mathrm{~N}$ \\
\hline I I & 60 & $\mathbf{F}$ & PG & I 8o/ I Io & I 86 & 13.5 & $10 \cdot 8$ & $8.4 \mathrm{~N}$ \\
\hline 12 & 63 & $\mathbf{F}$ & PC & $135 / 70$ & 147 & I $3 \cdot 1$ & $9 \cdot 3$ & $2.4 \sigma$ \\
\hline I 3 & 63 & $\mathbf{M}$ & GR & I 5o/80 & 74 & $5 \cdot 4$ & $7 \cdot 7$ & $4.8 \underset{\frac{0}{\Phi}}{\frac{0}{(1)}}$ \\
\hline \multicolumn{4}{|c|}{ GN $=$ Glomeruloneph } & \multicolumn{4}{|c|}{ AN $=$ Analgesic nephropathy } & \\
\hline \multicolumn{4}{|c|}{$\mathrm{PN}=$ Pyelonephritis } & \multicolumn{5}{|c|}{$\mathrm{GR}=$ Granuloma of unknown aetiology } \\
\hline \multicolumn{4}{|c|}{ PC $=$ Polycystitis } & & & & & 号 \\
\hline \multicolumn{9}{|c|}{$\begin{array}{l}\text { Received for publication June 5, } 1970 \\
\text { Address for reprints: Dr. M. Easterbrook, Department of Ophthalmology, I Spadina Crescent, Toronto r 79, Ontario, Canada } \\
\text { * At present Resident in Ophthalmology, Hospital for Sick Children, Toronto, Canada } \\
\text { ** Attending Staff, Toronto General Hospital, Toronto; Associate, Department of Ophthalmology, University of Toronto, Canada } \\
\text { ‡ Recipient of the Alumni Prize, University of Toronto, Ophthalmological Clinical Day, May 8, 1970 }\end{array}$} \\
\hline
\end{tabular}




\section{Method}

From July, 1969, to February, 1970, we examined thirteen patients in terminal renal failure at the Toronto General and Sunnybrook Hospitals, Toronto. All were examined for visual acuity and applanation pressure. Slit-lamp examination of the cornea and conjunctiva and retinal examination with the direct and indirect ophthalmoscopes and 3-mirror Goldmann lens were carried out. Fundus pictures were taken of all patients, and fluorescein angiography was performed in those who were well enough to tolerate the procedure. We measured blood pressures in the recumbent position, serum sodium, potassium, calcium, phosphorus, and creatinine, and blood urea nitrogen within 5 days of the ophthalmic examination. If a patient failed to respond to conservative treatment, had seizures, peripheral neuropathy, pericarditis, intractable nausea, vomiting, or pruritus, or was unable to work because of lethargy and fatigue, he was dialysed.

To assess the significance of any abnormal corneal and conjunctival findings, 200 eyes from roo control subjects were examined. The control series consisted of doctors, nurses, and nurse's aides who had no history of iritis, kidney disease, or recurrent conjunctivitis.

\section{Results}

The diagnosis, laboratory findings, certain ocular signs, and treatment for all patients are listed in the Table.

\section{A. VISUAL AGUITY AND INTRAOGULAR PRESSURE}

The vision in the majority of patients was excellent; corrected visual acuity in $2 \mathrm{I}$ of 26 eyes was 20/20. Case Io with 20/50 vision in the right eye had some exudates and pigment

\begin{tabular}{|c|c|c|}
\hline \multirow{2}{*}{$P$} & \multicolumn{2}{|c|}{ Conjunctival deposit } \\
\hline & $R$ & $L$ \\
\hline & + & + \\
\hline & + & + \\
\hline & + & + \\
\hline & + & + \\
\hline & - & + \\
\hline & + & + \\
\hline & ++ & ++ \\
\hline & - & + \\
\hline & + & + \\
\hline & + & + \\
\hline & + & + \\
\hline & + & + \\
\hline & + & + \\
\hline
\end{tabular}

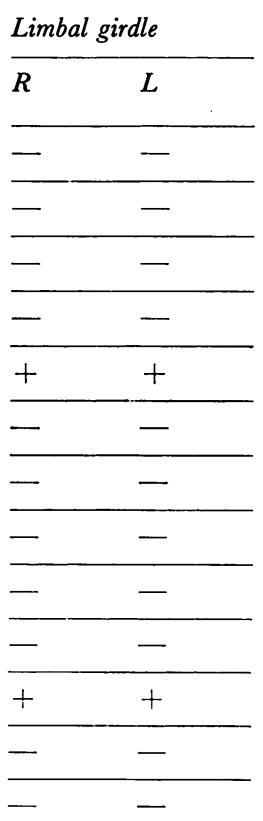

\begin{tabular}{ll}
\multicolumn{2}{l}{ Retinopathy grade } \\
\hline$R$ & $L$ \\
\hline IV & III \\
\hline III & III \\
\hline III & III \\
\hline III & III \\
\hline III & III \\
\hline I & I \\
\hline II & II \\
\hline III & III \\
\hline III & III \\
\hline IV & III \\
\hline I & I \\
\hline III & II \\
\hline III & III
\end{tabular}

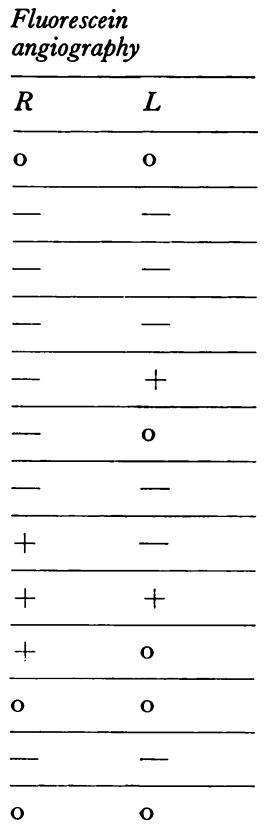

Treatment

H

G

$\mathrm{H}$

$\mathrm{H}$

C

$\mathrm{H}$

$\mathrm{H}$

G

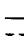

$\mathrm{H}$

C

$\mathrm{H}$

$\mathrm{P}$

C

$\mathrm{H}=$ Haemodialysis

$\mathrm{P}=$ Peritoneal

$\mathrm{C}=$ Conservative 
at the macula. Cases Io and 12 with 20/30 vision in one eye demonstrated macular exudates, and the two eyes (left eye of Case 2 and right eye of Case 9) with 20/200 vision were amblyopic from strabismus.

All applanation pressures were within normal limits; 25 of 26 eyes demonstrated a pressure of $17 \mathrm{~mm}$. $\mathrm{Hg}$ or less; the pressure in one eye was $20 \mathrm{~mm}$. $\mathrm{Hg}$.

\section{B. GORNEAL EXAMINATION}

Of 26 eyes, $2 \mathrm{I}$ were normal to slit-lamp examination. There was gross coarse material in the inferior cornea from 4 to 8 o'clock with a clear zone between this chalk-like material and the limbus in the right eye of Case 4 (Fig. I). Two of the three females in this series, Cases 5 and I I, showed the bilateral Vogt limbal girdle. Fig. 2 illustrates the increasing incidence of Vogt limbal girdle with age in the control series. Fig. 3 demonstrates the limbal girdle in the right eye of a 6o-year-old female control.

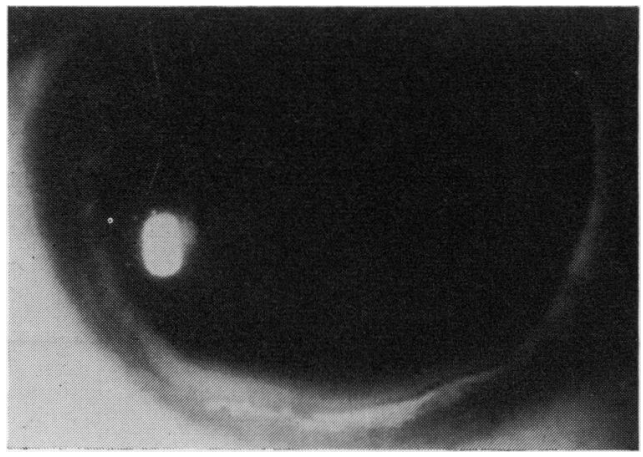

FIG. I Case 4, right eye, showing coarse chalky material, probably calcium. $\times 10$
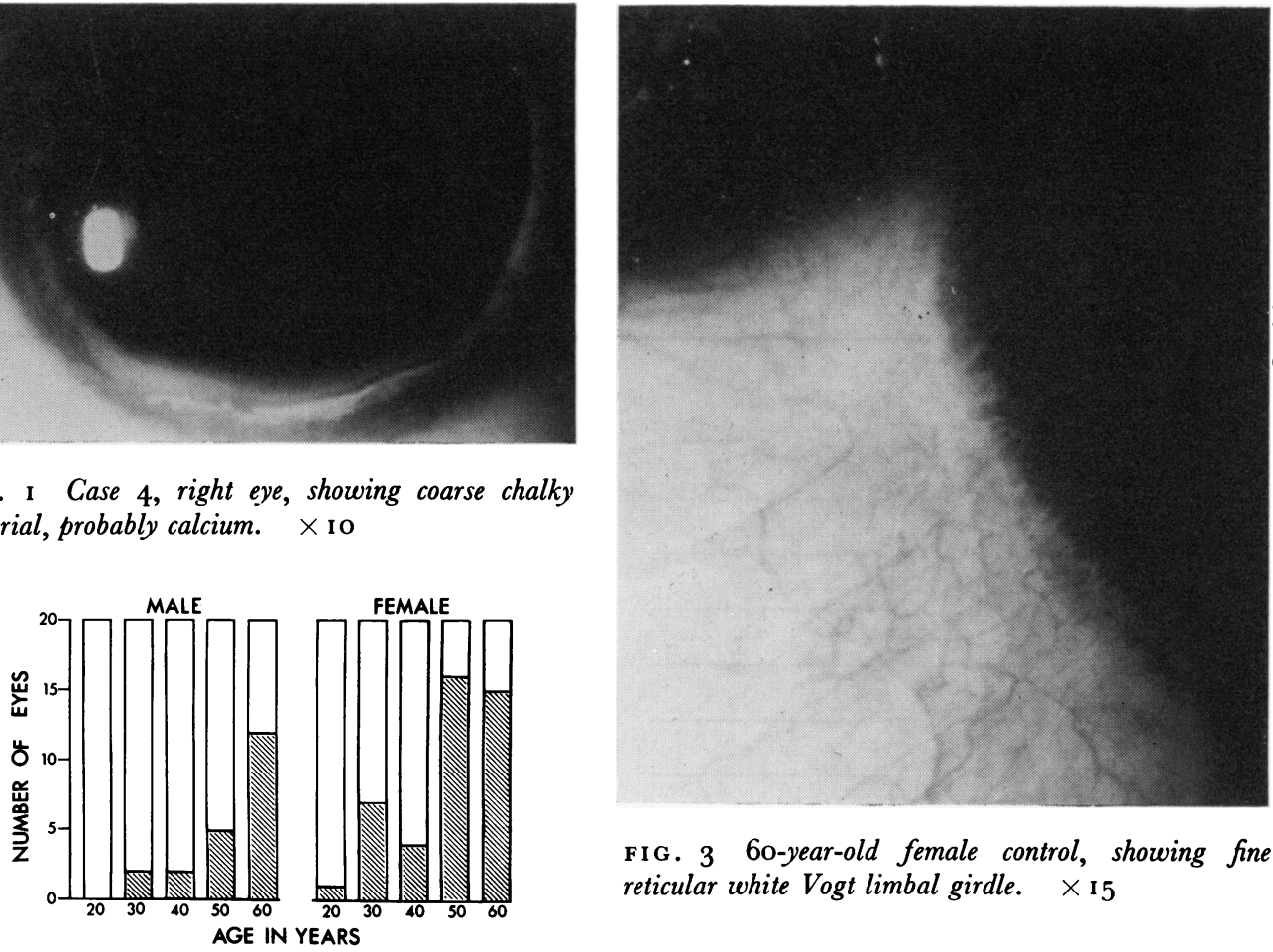

FIG. 3 6o-year-old female control, showing fine reticular white Vogt limbal girdle. $\times \mathbf{1 5}$

FIG. 2 Age and sex distribution of Vogt

limbal girdle in 200 eyes in 100 control patients.

\section{G. GONJUNGTIVAL EXAMINATION}

Among the 26 eyes in this series, only two were without conjunctival deposits; 24 had tiny, discrete, amorphous dull white deposits, usually in the interpalpebral area, most commonly in the lower temporal quadrants. These were often missed with focal illumination, but were easily seen with direct lateral illumination. Of the sixty eyes in males 
under 50 years of age in the control group (Fig. 4), only five showed any conjunctival abnormality, whereas fifteen of the sixteen eyes of uraemic male patients under 50 years old had conjunctival deposits. As there was only one female patient less than 50 years old in this series, the significance of such deposits in women is not known.

A biopsy of an asymptomatic white mass (Fig. 5) in the conjunctiva of Case 3 contained elastotic degeneration (Fig. 6). A von Kossa stain for calcium was negative on serial sections of the specimen.

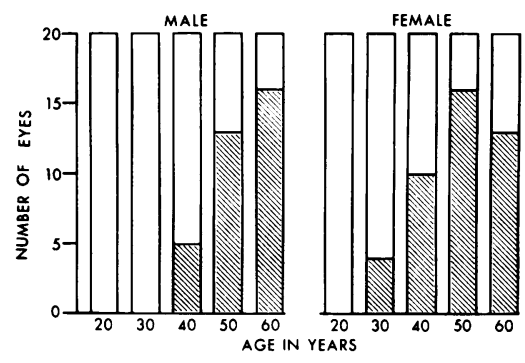

FIG. 4 Age and sex distribution of conjunctival deposits in 200 eyes in 100 control patients

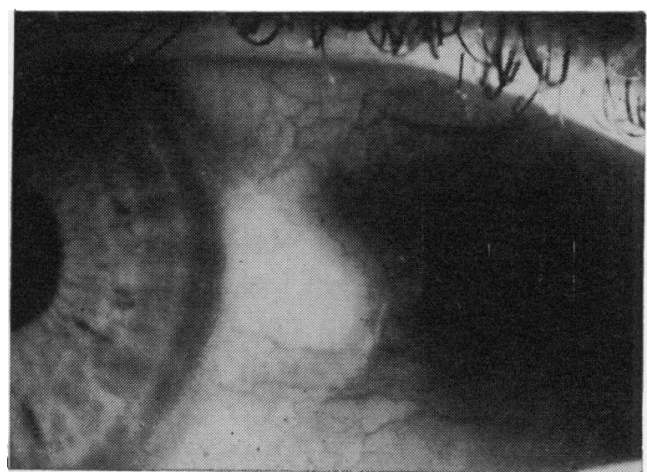

FIG. 5 Case 3 , right eye, showing asymptomatic pingueculae.

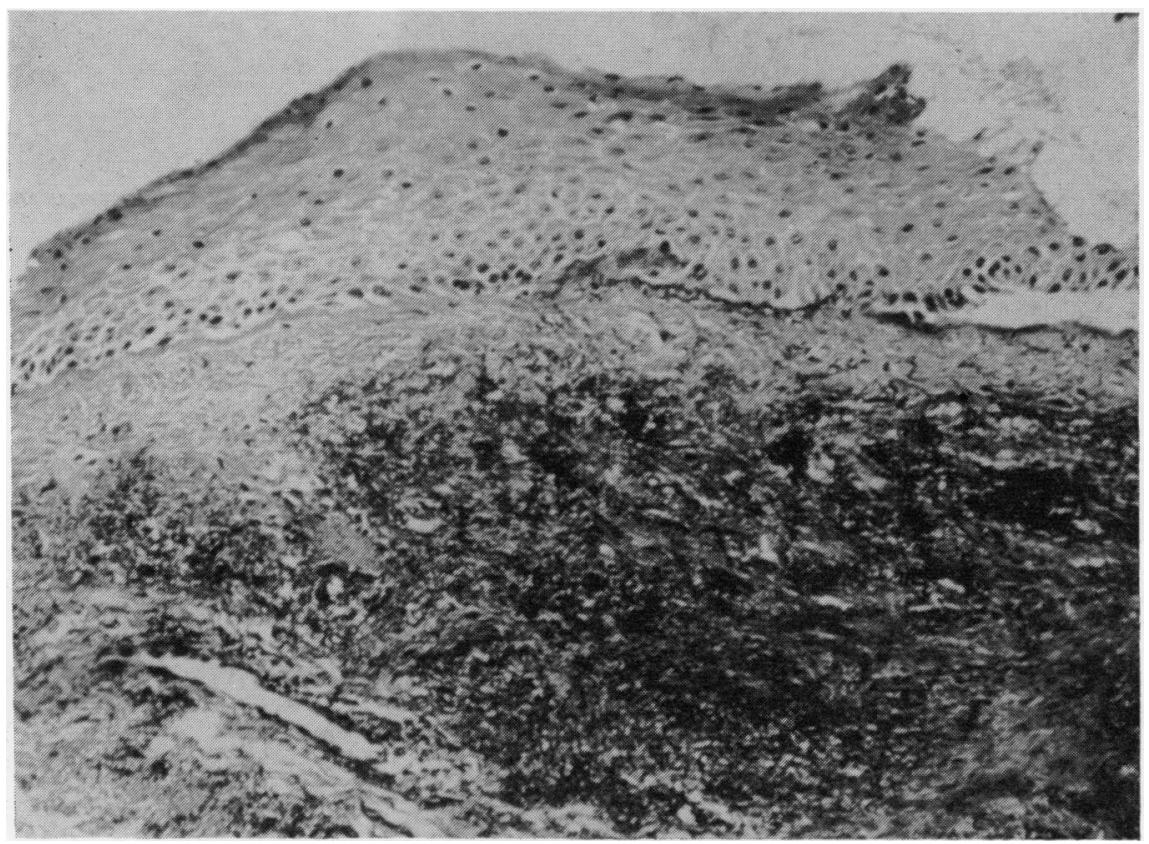

FI G. 6 Case 3, right eye, conjunctival biopsy, showing moderate elastotic degeneration. Elastic stain. $\times 75$

D. RETINAL EXAMINATION

(I) Retinal detachments

None was found in this study. 


\section{(2) Retinopathy}

The degree of retinopathy was estimated by the Keith-Wagener classification (Table). The majority of our patients had exudative and haemorrhagic changes in the retina on admission to hospital. There was only a general correlation between diastolic blood pressure and the degree of the retinopathy.

\section{(3) Fluorescein angiography}

Eight patients underwent bilateral and two patients unilateral angiography. Three patients were too nauseated or weak or both to undergo fluorescein studies. Most of the angiograms were normal (Table).

Case 9 had a perimacular leak in both eyes before haemodialysis, and 2 months later these were unchanged. Case ro had leakage around the right disc. In Case 8, a cottonwool spot obscured the fluorescein in the underlying artery in the arterial phase, but fluorescein leaked from dilated capillaries around this spot in the venous phase (Fig. 7). Case 5, a non-diabetic, had fluorescein leakage from an abnormal vessel inferior to the macula as well as an apparent microaneurysm in one eye.

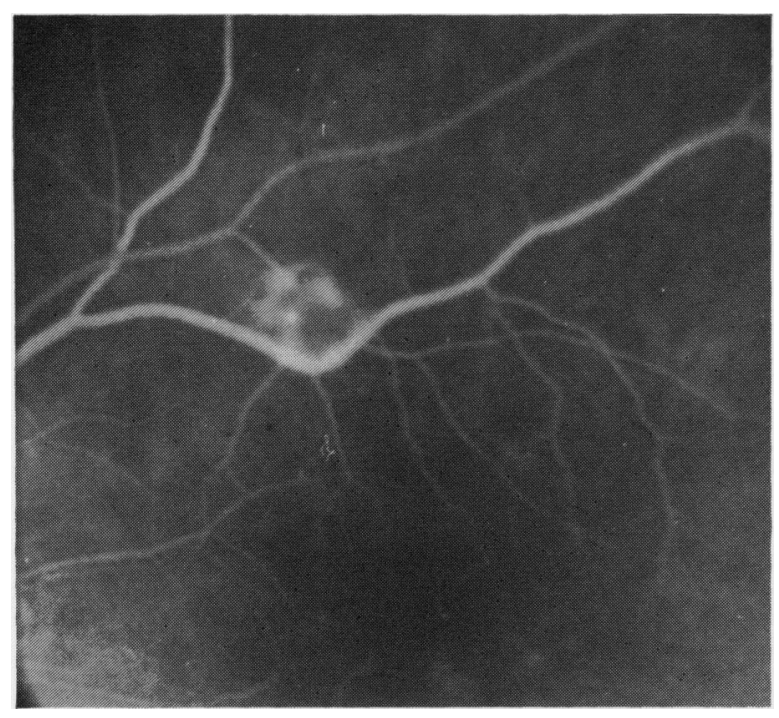

FIG. 7 Case 8, late venous phase; three microaneurysms, showing leakage

\section{Discussion}

In reviewing the results of this study we were particularly interested in the slit-lamp and fluorescein findings.

A. GORNEA

We were not suprised that two female patients, aged 34 and 60 years, had the Vogt limbal girdle, as one out of three of our female controls in their thirties and three out of four of our female controls in their sixties demonstrated this anomaly. Unlike Sugar and Kobernick (1960), we found the incidence of limbal girdle in women greater than that in men in all age groups.

We feel that Case 4 probably had a variant of band keratopathy because of the gross appearance of the cornea. The limbal opacity in this patient was neither granular nor 
limited in extent. The limbal area was sharp with the axial area trailing off in spots, as described by Duke-Elder and Leigh (1965a). Band keratopathy need not always be interpalpebral in position and may be patchy in distribution (Duke-Elder and Leigh, i $965 \mathrm{a})$.

To distinguish a Vogt limbal girdle from early band keratopathy is difficult but most important. Although Cogan, Albright, and Bartter (1948) stated that they were easy to distinguish, we agree with Abrams (1966) that this is not so. A lucid interval between the deposits and the limbus may occur in both early band keratopathy and the limbal girdle (Abrams, 1966). Indeed, reference has been made to the close histological resemblance between the two conditions (Duke-Elder and Leigh, 1965b), although Sugar and Kobernick (1960) thought that the marked fragmentation, elastotic degeneration, and absence of calcium suggested the histological picture seen in pingueculae.

\section{B. GONJUNGTIVA}

From the beginning of this study, we were impressed with the high incidence of dull, multiple, white conjunctival deposits, particularly in males under $5^{0}$ years of age ( 15 of 16 eyes).

Conjunctival injection was described in nine patients with chronic renal failure associated with an elevated mean $\mathrm{Ca} \times \mathrm{P}$ ratio (I I6); on the basis of one biopsy, the authors of this report concluded that their patients were subject to metastatic calcification (Berlyne and Shaw, 1967). They did not perform slit-lamp examinations. The conjunctival lesions in hypercalcaemia described by Walsh and Howard (1947) as "probable calcium" were crystal-clear glass-like particles, unlike the deposits seen in our uraemic patients.

White irregular opacities similar to those we describe were noted in one of the uraemic patients reported by Cogan and others (1948). The pathogenesis of the conjunctival deposits we found is unknown and deserves further study. However, we feel that incidence in patients with chronic renal failure is significant, particularly in males under 50 years of age. We intend to follow these patients to ascertain whether dialysis has any effect on these interesting opacities.

\section{FLUORESGEIN ANGIOGRAPHY}

The results of our fluorescein studies were equivocal. They provided no better additional prognostic information than fundus photography. In Case 8, we observed the microaneurysms and leaking capillaries described by Gass (1968) as frequently seen around areas of poor capillary perfusion (Fig. 7). Gass (1968) stated that many patients with hypertension and decreased visual acuity showed no paramacular leakage. He suggested, therefore, that the macular star and exudates were due to retinal ischaemia, and were unrelated to leakage from retinal vessels. Although we can confirm this finding in Case Io, who had a visual acuity of 20/5o because of exudate and pigment, Gase 9 with bilateral exudates showed bilateral paramacular leakage which did not respond to haemodialysis.

\section{Conclusion}

In this study we have examined patients in chronic renal failure in order to identify the ocular findings and determine whether the ocular status of uraemic patients is an indication for dialysis. 
We found no retinal detachments in our patients. In recent years facilities for dialysis have become available in many centres, and the criteria for admission to a dialysis programme are changing, so that patients are now dialysed at a much earlier stage of their renal disease. Consequently, we are seeing fewer patients with severe retinopathy $\Rightarrow$ Only two of the 26 eyes examined in this study were classified as cases of Grade IV retino=0 pathy.

This study revealed conjunctival deposits in all uraemic male patients under 50 years of age. Although the pathogenesis of these discrete deposits is unknown, we feel their incid $-\frac{\mathbb{}}{\circ}$ ence is significant and warrants further study. We intend to examine patients with less severe renal disease to assess the prognostic implications of this observation.

\section{Summary}

Thirteen patients with chronic renal failure were examined with the slit lamp, indirecto ophthalmoscope, 3-mirror contact lens, and retinal photography. Fluorescein angiography was performed on ten patients. Visual acuity was excellent in all eyes not amblyopic. A very high incidence of conjunctival deposits was observed, particularly in males $N$ less than 50 years old. There were no retinal detachments. The fluorescein angiograms had little practical prognostic value but demonstrated the microaneurysms, poor capillary perfusion, and paramacular leakage occasionally seen in hypertension. The ocular statuso of these patients did not influence the decision to commence dialysis.

We should like to thank Dr. D. Wilson of the Toronto General Hospital, Dr. D. Charron and Miss Ann Sloan of Sunnybrook Hospital, and Dr. H. Reid and her Department of Medical Publications of the Hospital Sick Children for their help in the preparation of this article.

\section{References}

ABRAMS, J. D. (ig66) Proc. roy. Soc. Med., 59, 533

BERLYNE, G. M., and SHAW, A. B. (1967) Lancet, $\mathbf{1}, 4$

Bosco, J. A. s. (I96I) Amer. J. Obstet. Gynec., 82, 208

buchanan, w. s., and ellis, P. P. (1964) Arch. Ophthal. (Chicago), 7r, 182

GOGAN, D. G., Albright, F., and BARTTER, F. G. (1948) Ibid., 40, 624

DUKe-Elder, S., and Leigh, A. G. (I965a) "A System of Ophthalmology", vol. 8, Pt II, pp. 894

Kimpton, London

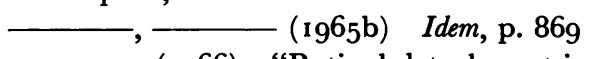

EDITORIAL (1966) "Retinal detachment in renal failure", Brit. med. F., 2, 54 I

ELlis, P. P., and FONKEN, H. A. (1966) Arch. Ophthal. (Chicago), 75, 36

GASS, J. D. M. (1968) Ibid., 80, 569

LAPCO, L., Weller, J. M., and GreEne, J. A. (1965) Ann. intern. Med., 63, 76o

METTIER, S. R., JR. (196I) Arch. Ophthal. (Chicago), 65, 386

PARIS, G. L., and MACOUL, K. L. (I969) Amer. F. Ophthal., 67, 249

SHARPSTONe, P., and LEe, H. A. (1966) Brit. med. F., 2, 92

STEINESS, I. (1968) Acta med. scand., 183, 225

SUgar, h. s., and Kobernick, s. (1960) Amer. F. Ophthal., 50, io I

WALSH, F. B., and HOWARD, J. E. (1947) $\quad$ J. clin. Endocr., 7, 644 